\title{
Energy-financial flows of an enterprise
}

\author{
Galina Klimova ${ }^{1, *}$, and Veronika Morozova ${ }^{1}$ \\ ${ }^{1}$ National Research Tomsk Polytechnic University, 634050 Tomsk, Russia
}

\begin{abstract}
Energy, financial, material and other interrelation set common presentation formed on enterprises can be sum in energy-financial flows. Such balances composition and analysis regular practice provides during several flows forming determine contradictions in time, put value of energy efficiency indexes. And, in case of their increasing quickly make management decision. In this way energy-financial balance is enterprise operating management.
\end{abstract}

Fuel and energy balances are important and sustainable device of energy facility exploitation's efficiency control and analysis. The most interesting and less spread apart energy balances that are in monetary value [1].

Such balance can be used for energy industry's analysis and planning, for quality control of energy-saving and energy resources utilization efficiency improvement measures, for production development programme energy efficiency values estimation. Balance shows energy resources production and consumption volumes of reasonable time, money resources income and expense, fuel storage, energy resources plant demands and utility networks losses, energy resources consumption volumes of organization units according to uses [1 7].

There can be designed a model for common whole set of energy, financial, material and other interrelations performance between energy resources packagers and consumers, where these interrelations are presented as flows simulated by network graphs [8].

Energy flows form energy balance that remains as base for lots infrastructural solutions connected with development designing, planning and on-line controlling of areal economy.

Energy balance, because of its physical nature severity, radically can be formed for any arbitrary short period and any arbitrary small site.

Financial flows incidental with energy flows and expressing bought and sold energy resources cash compensation are formed differently. It is hugely complicated to build financial balance for short periods and small sites. Some energy flows do not have responsive financial flow, and some financial flows are generated not by energy flows, but by their realization conditions. Financial flows are greatly varying in time, and small sites financial flows generally do not have recordkeeping. Today standard coasts division into semi-variable (in power industry - fuel, energy, water and etc.) and semi-constant (amortization, salary, taxes and etc.) essentially does not change temporary inequality. Because of it supposed energy and financial flows spread pattern accordance generally in fact is out of a place.

\footnotetext{
${ }^{*}$ Corresponding author: gariki@,tpu.ru
} 
Energy-financial balance scheme represents graph, branches of which are company interrelationships (resources flows) with objects (graph nodes). Such scheme analytic image is incidence matrix. This matrix elements are formed following way: signals about energy, financial, material and service flows availability and sign are put into matrix columns. Objects having relationship with company (contractors) are put into matrix rows. At the intersection of relevant column and row should be put 1 or 0 in dependence of availability or no-flow condition. Flow direction form its sign: if "plus" -flow directed to company, and if "minus" - flow directed to opposite side.

Matrix fuel elements detailing provides to form fuel balance, and financial elements financial balance.

Simulated energy company indexes are presented in the tables for visual reference. Table 1 shows some process statements.

Table 1. Annual rate of company activity.

\begin{tabular}{|c|c|c|c|c|}
\hline Ser.No. & Characteristics & Targets & Actuals & Notes \\
\hline 1 & Energy generation, mil. kWh & 3600 & 3410 & \\
\hline 2 & Energy purchase at wholesale market, mil. kWh & 1400 & 1599 & \\
\hline 3 & Electricity consumption for auxiliaries, mil. kWh & 288 & 273 & \\
\hline 4 & Energy networks losses, mil. kWh & 528 & 530 & \\
\hline 5 & Productive supply, mil. kWh & 4184 & 4206 & \\
\hline 6 & Fuel purchase volume, toe & 13.0 & 12,28 & $\begin{array}{c}1.364 \\
\text { mil. tfoe. }\end{array}$ \\
\hline 7 & Maximum load utilization time, hour & 5500 & 5470 & \\
\hline
\end{tabular}

There is got information about relationships with separate consumers, several levels budgets and markets by elements of matrix rows.

Company budget divides received electrical energy sale proceeds into planning and reporting proceeds items. Table 2 shows an example.

Table 2. Company expenditures, mil. RUR.

\begin{tabular}{|c|c|c|c|c|}
\hline Ser.No. & Characteristics & Targets & Actuals & Notes \\
\hline 1 & $\begin{array}{c}\text { Fuel payment including stock reserve } \\
\text { forming }\end{array}$ & 280.2 & 3410 & 0.789 \\
\hline 2 & Purchased electrical energy payment & 188.9 & 215.8 & 0.05 \\
\hline 3 & Salary & 120.8 & 100.3 & 0.02 \\
\hline 4 & Amortization payments & 55.7 & 55.4 & 0.01 \\
\hline 5 & Operating costs & 403.5 & 382.2 & 0.09 \\
\hline 6 & Taxes and fees & 48.6 & 46.0 & 0.02 \\
\hline 7 & Other & 120.8 & 114.4 & $0.03 \backslash 4324.1$ \\
\hline
\end{tabular}

Costs some aspects influence on consumers energy production cost is determined by aggregates:

$\checkmark \quad$ Average consumers energy production coast;

$\checkmark \quad$ Specific fuel equivalent consumption for electric generation;

$\checkmark \quad$ Fuel factor of energy production coast.

Relationships with region electricity company all levels budgets are built on principle of salary and taxes payment priority relative to others. Company pay taxes:

$\checkmark$ for profits;

$\checkmark$ for added coast;

$\checkmark$ of personal income tax;

$\checkmark$ for land;

$\checkmark \quad$ for mineral resources extraction and natural resources using; 


\section{$\checkmark \quad$ of road faund;}

Company budgetary payments are compensation for public services that mean services having public significance and supplied in terms of legistrated conditions.

By this way energy and financial flows model based on incidence matrix forming provides to estimate wide range of current and integrated indexes. For sure, energy-financial balance is of the utmost interest because it consists information about cash flow connected with energy resources production and using.

Firstly, energy balance is formed in tangible form of each utilizable resource, then in monetary units. Synthetical balance in monetary units provides to outline energy efficiency upgrading ways - consumption reduction, replacing some energy resources to others or resources consumption cost reduction. Boxes, districts, subdivisions, installations analysis of balance expense side helps to find out losses centers and provide means to decrease them.

Considering relative energy resources replaceability, current cost changing and each resource quantity balance can be optimized not only by losses decreasing but also by the way of structural adjustment.

Energy-financial flows formed model using example can be forecast changes of contributing factors on electricity company production and realization cost. In this case, research facility resides in significant model portability in comparison with company actual financial system.

- fuel tariff,

- energy consumption rate,

- electricity sales tariff,

- $\quad$ purchased electricity tariff,

- taxes changes rate,

- electricity distribution and transport cost,

- distribution services cost,

- average salary changes rate,

- $\quad$ repair, connection, transport and other services tariff,

- $\quad$ system operator service tariff,

Investigation of factors changing influence on energy production cost is done by planning method providing upgrade simultaneously large number of variables (factors) and to find target interrelationships.

For a wide range of factors, each influence research by turns leads to large number of experiments. With that, synergies between factors are not explored. Average (basic) factors value set to level achieved in base year, and variation intervals make values corresponding factors changing in range of $\pm 5 \%$ from base level.

\section{Conclusion:}

Common spatiotemporal energy and financial flows of energy company visualization indicates about structural observable processes determinism, it provides to use universal mechanisms during operational and strategic decisions. Analysis mechanisms versatility provides to solve many control problems.

Energy-financial balances using provides to look over financial flows values and directions in front of energy flows, it forms competitive position.

\section{References}

1. GOST 27322-87. Power plant balance. Main principles [in Russian] 
2. GOST P 51379-99. Energy performance certificate of fuel and energy resources power consumer [in Russian]

3. G.N. Klimova, V.V. Litvak, Seven problems and seven keys of energy saving (Red banner, Tomsk, 2013) [in Russian]

4. A.S. Nekrasov, Yu.V. Sinyak, Power plant engineering control (Energiya, Moscow, 1979) [in Russian]

5. Yu.N. Savenko, E.O. Steinhaus, Energy budget (Energiya, Moscow, 1971) [in Russian]

6. S.M. Romanov, G.F. Alekseev, Mountainous research and information bulletin, 1, 12 (2010) [in Russian]

7. V.V. Litvak, Zonal energy saving basis (STT, Tomsk, 2002) [in Russian]

8. V.V. Litvak, G.Z. Markman, M.I. Yavorskiy, Industrial energetics, 5 (2004) [in Russian]

9. E.I. Borisov, I.M. Lyskov, D.Yu. Alexandrov, E.E. Borisova, Electric power industry economy and finances, 9 (2003)

10. Retail (consumers) market electrical (thermal) power regulated tariffs and costs calculation methodology instructions. Approved by the RF Federal Energy Commission 31.07.2002 [in Russian]

11. A.V. Fedchenko, Economics and finance of electric power industry, 7, 151 (2004) [in Russian]

12. G.N. Klimova, V.V. Litvak, Origins of energy saving (STT, Tomsk, 2016) [in Russian] 